\title{
Gay Men's Use of Condoms With Casual Partners Depends on the Extent of Their Prior Acquaintance
}

\author{
Evelien Rouwenhorst · Kylie-Ann Mallitt • \\ Garrett Prestage
}

Published online: 30 November 2011

(C) The Author(s) 2011. This article is published with open access at Springerlink.com

\begin{abstract}
Unprotected anal intercourse with casual partners (UAIC) is the strongest predictor of HIV incidence among gay men. Familiarity between sex partners has been associated with likelihood to engage in UAIC, but the decision to use condoms with partners who are previously acquainted is complex and multifaceted. Using data from the Pleasure and Sexual Health survey 2009, we investigated the association between aspects of familiarity with casual partners and disclosure of HIV serostatus. Compared with occasions when they engaged in protected anal intercourse (PAIC), when men engaged in UAIC they were more likely to report having previously met their partners (PAIC 45.9\%; UAIC 54.9\%), knowing them very well (PAIC 7.9\%; UAIC 19.7\%), and having previously had sex with them (PAIC 32.2\%; UAIC 44.8\%) (McNemar $P<0.001)$. Men were also more likely to disclose their HIV serostatus to their casual partners on occasions of UAIC, were more confident they knew their partner's HIV serostatus and trusted them more. Overall, UAIC was associated with both the broad concept of 'familiarity' (composed of elements of prior acquaintance and trust) and HIV disclosure. When men engage in UAIC without some prior familiarity, disclosure of HIV serostatus, or confidence and trust in their partners, they are probably at
\end{abstract}

E. Rouwenhorst · K.-A. Mallitt · G. Prestage

Kirby Institute, University of NSW, Sydney, Australia

E. Rouwenhorst $(\square)$

VU University, Amsterdam, The Netherlands

e-mail: rouwenhorstevelien@ hotmail.com

G. Prestage

Australian Research Centre in Sex Health and Society,

La Trobe University, Bundoora, Melbourne, Australia greater risk than on occasions when they engage in UAIC with partners with whom they do have these qualities. However, for some men, their trust in knowing specific details about their partners may not always be wellinformed or reliable. These different circumstances are challenging for HIV prevention work.

Keywords HIV · Familiarity · HIV disclosure · Unprotected anal intercourse casual partners - Gay men

\section{Introduction}

Increasingly, many gay men have adopted strategies that they believe minimize the risk of HIV transmission, such as reliance on sero-sorting, undetectable viral load and strategic positioning during unprotected anal intercourse (UAI) [1-3]. The risk of transmission associated with these specific behaviors is less than it is with receptive UAI with an HIV-positive partner, but remains higher than for condomprotected intercourse [4]. Such risk-reduction strategies often rely on a degree of familiarity with the men's sex partners, and men often make assumptions regarding the HIV serostatus of their casual partner [5-7].

Crosby et al. [8] found that about one in five men who reported being HIV-negative had not been tested in the past year, and $5.3 \%$ of all men had never been tested. Testing rates may differ regionally, nationally and internationally, as well as over time. Recent Australian research found that $23.0 \%$ of the men recruited from social venues had never been tested for HIV [9]. Despite a high proportion of men accurately self-reporting their HIV status, $20 \%$ of the men were unaware of their infection; identified as having unrecognized infections. Some of these men engaged in unprotected anal intercourse with casual partners (UAIC) 
and disclosed their HIV status to their casual partner, but this disclosure does not reflect their true HIV status. These findings suggest that, at least for a minority of the men, sero-sorting may not always be reliable. In recent years, in Australia, increasing proportions of men disclose their HIV serostatus with casual partners [10]. This has corresponded with a period of increases in the proportion of men who report that their UAIC is restricted to men of the same HIV serostatus [11]. Koblin et al. [12] found that men were more likely to report UAIC with partners they perceived to be seroconcordant. Davidovich et al. [13] found that in some regular relationships partners perceive UAI to be a symbol of trust. This is associated with less condom use between regular partners, and also with a higher likelihood that men established they were HIV-negative seroconcordant with their partner. This may also be the case with some casual partners. Casual sex encounters are very diverse, partners may know each other well or to some extent, or partners are completely anonymous [1]. Especially when men become more familiar with their casual partner, trust may play an important role when negotiating unprotected sex.

Disclosure of HIV serostatus is probably more likely as men become more familiar with their casual partners. This suggests that revealing or discussing one's HIV serostatus is a marker of intimacy or growing trust between partners [14]. Prestage et al. [1] also found that discussion and use of condoms during casual sexual encounters are affected by the degree of familiarity. The degree of familiarity and the particular ways in which they view their relationship with each other affect their behavior with each other, and may have implications for negotiation of condom use. The Health in Men (HIM) study has shown that prior acquaintance with casual partners is associated with perceived knowledge of a partner's serostatus and a decreased likelihood to use condoms, and being more intimately acquainted with someone appears to be an important consideration in decisions about condom use [15]. Zablotska et al. [16] showed that familiarity with and a history of prior sex with casual partners is associated with UAIC, regardless of partner's HIV serostatus. However, a false sense of trust may increase the risk of HIV transmission among gay men.

In this study, we investigated men's considerations for not using condoms with casual partners. We focused on familiarity with casual partners, and the role of disclosure of HIV serostatus. Therefore, we examined the last occasions of protected and unprotected anal intercourse with casual partners among gay men in Australia who had engaged in both UAIC and protected anal intercourse with casual partners (PAIC) in the previous 12 months, to identify what differences there might be in the circumstances of these two sorts of occasions.
The key issues examined in this article were:

- How well do gay men know their casual sex partners?

- How does familiarity with casual partners affect decisions about condom use?

- How does trust in casual partners affect the decisions about condom use?

- What is the relationship between familiarity with casual partners, and assumed knowledge of partner's HIV serostatus and its effect on likelihood to engage in UAIC?

\section{Methods}

We used an anonymous online behavioral and attitudinal survey to investigate the attitudes and beliefs about condom use, and familiarity with and trust in their last casual partner and the risks of HIV transmission among Australian gay men in a large community-based sample. Ethics approval was obtained from the University of New South Wales and La Trobe University.

\section{Questionnaires}

In addition to questions about men's condom use in the previous year and most recent sexual encounters, and familiarity with and trust in their casual partner, the online questionnaire included demographic items, and questions on sexuality and gay community engagement.

\section{Participants}

Men were eligible for the study if they were homosexuallyidentified or had had sex with another man in the previous year, and they lived in Australia. Participants were recruited through gay community events and venues, and online. Of 4,479 surveys started, 2,306 men completed the questionnaire. Most of those who did not complete the questionnaire failed to proceed beyond the first few questions, indicating that they were most likely curious visitors who were not actually interested in participation. Nonetheless, these initial questions included mainly demographic characteristics, and there was no difference between those completed these few items but did not proceed further and those completed the survey. There were 543 men who reported both PAIC and UAIC in the previous 12 months, and these men were included in the analyses reported here. The men in our study were very similar to all other men who completed the survey (Table 1). The only differences between these 543 men and the rest of the sample were that they had a slightly higher mean age, and were more likely to be HIV positive. 
Table 1 Characteristics of the sample

\begin{tabular}{|c|c|c|c|c|}
\hline & $\begin{array}{l}\text { Men who engaged in both } \\
\text { UAIC and PAIC } N=543 \\
(\%)\end{array}$ & $\begin{array}{l}\text { Men who engaged in } \\
\text { PAIC only } N=1302 \\
(\%)\end{array}$ & $\begin{array}{l}\text { Men who engaged in } \\
\text { UAIC only } N=617 \\
(\%)\end{array}$ & $\begin{array}{l}\text { All men who completed } \\
\text { the survey } N=2306 \\
(\%)\end{array}$ \\
\hline Mean age (years) & 36.9 & 36.0 & 37.1 & 35.1 \\
\hline \multicolumn{5}{|l|}{ Education } \\
\hline Less than university-level & $250(46.0)$ & $550(42.2)$ & $297(48.1)$ & $1069(46.4)$ \\
\hline University-level & $293(54.0)$ & $752(57.8)$ & $320(51.9)$ & $1237(53.6)$ \\
\hline \multicolumn{5}{|l|}{$\begin{array}{l}\text { Belief about own HIV } \\
\text { serostatus }\end{array}$} \\
\hline HIV-positive & $100(18.4)$ & $147(11.3)$ & 115 (18.6) & $224(9.7)$ \\
\hline HIV-Negative & $441(81.2)$ & $1153(88.6)$ & $500(81.0)$ & $2076(90.0)$ \\
\hline Unknown & $2(0.4)$ & $2(0.2)$ & $2(0.3)$ & $6(0.3)$ \\
\hline \multicolumn{5}{|l|}{ Homosexual identity } \\
\hline Gay & $413(81.6)$ & $968(80.8)$ & $466(81.0)$ & $1681(80.5)$ \\
\hline Homosexual & $34(6.7)$ & $82(6.8)$ & $42(7.3)$ & $142(6.8)$ \\
\hline Bisexual & $54(10.7)$ & $127(10.6)$ & $61(10.6)$ & $215(10.3)$ \\
\hline Heterosexual & $0(0.0)$ & $2(0.2)$ & $0(0.0)$ & $8(0.4)$ \\
\hline Unsure & $5(1.0)$ & $19(1.6)$ & $6(1.0)$ & $41(2.0)$ \\
\hline \multicolumn{5}{|l|}{ Gay community involvement } \\
\hline Not at all & $133(24.8)$ & $316(24.4)$ & $155(25.4)$ & $624(27.4)$ \\
\hline Not very & $244(45.4)$ & $575(44.4)$ & $276(45.2)$ & $1021(44.8)$ \\
\hline Somewhat & $120(22.3)$ & $313(24.2)$ & $135(22.1)$ & $500(21.9)$ \\
\hline Very & $40(7.4)$ & $90(7.0)$ & $44(7.2)$ & $133(5.8)$ \\
\hline \multicolumn{5}{|l|}{ Gay friends } \\
\hline None & $19(3.5)$ & $42(3.2)$ & $23(3.8)$ & $91(4.0)$ \\
\hline Few & $136(25.3)$ & $336(26.0)$ & $154(25.2)$ & $643(28.2)$ \\
\hline Some & $184(34.2)$ & 461 (35.6) & 207 (33.8) & $820(35.9)$ \\
\hline Most & $188(34.9)$ & $438(33.8)$ & $217(35.5)$ & 698 (30.6) \\
\hline All & $11(2.0)$ & $17(1.3)$ & $11(1.8)$ & $31(1.4)$ \\
\hline
\end{tabular}

Analysis

Descriptive statistics were used to compare occasions of UAIC with occasions of PAIC. The McNemar's test was used to examine the significance of univariate relationships between the items asked for both sorts of encounter: degree of familiarity with the partners involved and knowledge of their HIV serostatus. Familiarity was measured by the following questions: 'How well did you feel you knew him at the time?', 'When did you meet him?', 'Had you previously had sex with him?', 'How much did you feel you could trust him on that occasion?'. Disclosure of HIV status was measured by the following questions: 'What did you believe was his HIV status on that occasion?', 'Did you tell him your own HIV status?', 'When did he tell you his HIV status?', 'How confident were you that this was his HIV status?'. Men were asked about their most recent HIV test results and what they believed their current HIV serostatus to be. Decisions about disclosure of HIV serostatus and condom use detailed in this article relied on men's perception of their current HIV serostatus and so men's belief about their current HIV serostatus was used in these analyses.

Multivariate analyses were conducted to identify patterns of behavior which were separately associated with engaging in UAIC and PAIC, using principal components analysis (PCA) and a hierarchical cluster analysis (HCA). In PCA, tetrachoric correlations were used, and eigenvectors with an eigenvalue greater than one were retained. Principal components (PCs) were rotated using an oblique oblimax rotation, reflecting the correlation between the included variables, and PC loadings with an absolute value greater than 0.4 were interpreted to be statistically relevant. Repeated measures logistic regression was used to determine if there was a significant association between the PCs retained in the analysis, and occasions when men engaged in PAIC and UAIC. Descriptive statistics were used to identify the direction of this association. 
In HCA the distance between individuals was calculated using squared-Euclidian distance. Agglomerative hierarchical cluster analysis with Ward's linkage method was used. Dendograms were created to visualize clusters and determine how many clusters to retain in the analysis. The relationship between clusters and occasions when men engaged in PAIC and UAIC was determined with repeated measures logistic regression, and descriptive statistics were used to identify the direction of this association. All analyses were conducted in SPSS v19.

\section{Results}

Respondents were mainly recruited through the internet. The 543 men who reported both UAIC and PAIC in the previous 12 months ranged in age from 15 to 74 years old, with a mean of 36.9 years (Table 1).

The majority of the sample were university educated. Most identified as gay or bisexual, with $57.0 \%$ 'very much' identifying as gay. A third said most of their friends were gay and the majority spent at least some free time with gay friends. About 30\% were at least somewhat involved in the gay community. When asked what they believed their own HIV serostatus to be, $18.4 \%$ of the men reported they believed they were HIV-positive, $81.2 \%$ believed they were HIV-negative, and the remaining $(0.4 \%)$ were unable to indicate whether they were HIV-positive or HIVnegative.

Six men $(1.2 \%)$ reported just one casual partner in the previous 6 months. Nearly half $(44.2 \%)$ of men had between 2 and 10 partners, and $54.6 \%$ had more than ten casual partners in the previous 6 months.

In $75.3 \%$ of the cases both events occurred within the previous 6 months; $16.2 \%$ of the cases PAIC occurred in the previous 6 months, while UAIC occurred in the previous 7-12 months; $5.7 \%$ of the cases PAIC occurred in the previous 7-12 months, while UAIC occurred in the previous 6 months; and in $2.8 \%$ of the cases both events occurred in the previous $7-12$ months. 87 men $(16.0 \%)$ reported that the partner on both the UAIC and PAIC occasions was, in fact, the same man, including 42 men (7.7\%) who reported that the UAIC and PAIC had both occurred on the same occasion.

There was little difference in reported drug use between occasions when men engaged in UAIC $(45.5 \%)$ and occasions when they engaged in PAIC $(48.6 \%)$. There was also little difference between UAIC and PAIC regarding where this sexual encounter occurred, with most men reporting that it occurred at home $36.6 \%$ during PAIC and $31.5 \%$ during UAIC) or at the home of their partner on this occasion $(26.3 \%$ during PAIC and $32.4 \%$ during UAIC).
Familiarity With and Disclosure of HIV Serostatus to Casual Partner

On occasions when men engaged in UAIC they were more likely to believe their partner was HIV-positive than on those occasions when they engaged in PAIC, and they were more likely to have been informed of this by their partner on those occasions as well (Table 2). Three quarters of the HIV-positive men $(73.0 \%)$ indicated their most recent UAIC partner was also HIV-positive but this was true of only $17.0 \%$ of their most recent PAIC partners. Men were more likely to report they did not know their partner's HIV serostatus when they engaged in PAIC than when they engaged in UAIC. The majority of the men were confident about their reported knowledge of the HIV serostatus both of the partner with whom they engaged in UAIC and of the partner with whom they engaged in PAIC. The majority of men who had been told their most recent UAIC partner's HIV serostatus were very confident or certain about this knowledge: Of the 196 men whose most recent UAIC partner reported being HIV-negative, 120 men $(61.2 \%)$ reported being very confident or certain of this knowledge. However, of the 180 men whose most recent PAIC partner reported being HIV-negative, only 85 men (47.2\%) reported being very confident or certain that this was correct.

On occasions when men engaged in UAIC, they reported that their partners were more likely to disclose their HIV serostatus than on those occasions when they engaged in PAIC. This disclosure took place either prior to sex on this occasion, or on a previous occasion. When the disclosure occurred after they had sex, it was interpreted as 'no disclosure' for this analysis. Mostly, when disclosure occurred it was mutual: 221 of 248 men (89.1\%) whose partner disclosed his HIV serostatus on those occasions when they engaged in UAIC, also told that partner their own HIV serostatus. There was little difference between HIV-positive men and men who were not HIV-positive in this regard.

In $40.2 \%$ of occasions when men engaged in UAIC, they did so with a partner who had informed him he was seroconcordant: $7.7 \%$ were seroconcordant HIV-positive and $32.5 \%$ were seroconcordant HIV-negative. However, most men nonetheless believed that these UAIC partners were in fact seroconcordant. $86.0 \%$ of men believed their partner was seroconcordant: $13.4 \%$ believed they were seroconcordant HIV-positive and $72.6 \%$ believed they were seroconcordant HIV-negative. Of occasions when men engaged in PAIC, less than one-third $(29.1 \%)$ had been told by his partner that he was seroconcordant: $0.4 \%$ were seroconcordant HIV-positive and $28.7 \%$ were seroconcordant HIV-negative. Nonetheless, men were inclined to believe that most of their PAIC partners were also seroconcordant. 
Table 2 Descriptions of most recent casual partner on occasions of UAIC and PAIC

\begin{tabular}{|c|c|c|c|}
\hline$N=543(\%)$ & $\begin{array}{l}\text { UAIC } \\
\text { occasion }\end{array}$ & $\begin{array}{l}\text { PAIC } \\
\text { occasion }\end{array}$ & $\begin{array}{l}P \text {-value } \\
\text { (McNemar) }\end{array}$ \\
\hline \multicolumn{4}{|l|}{ Partner's reported HIV serostatus } \\
\hline Unknown & $295(54.3)$ & $360(66.3)$ & \multirow[t]{3}{*}{$<0.001$} \\
\hline HIV-positive & $52(9.6)$ & $3(0.6)$ & \\
\hline HIV-negative & $196(36.1)$ & $180(33.1)$ & \\
\hline \multicolumn{4}{|c|}{ Belief about partner's HIV serostatus } \\
\hline Unknown & $17(3.1)$ & $16(2.9)$ & \multirow[t]{3}{*}{$<0.001$} \\
\hline HIV-positive & $109(20.1)$ & $33(6.1)$ & \\
\hline HIV-negative & $417(76.8)$ & $494(91.0)$ & \\
\hline \multicolumn{4}{|l|}{ Knew partner before } \\
\hline No/a little & $436(80.3)$ & $500(92.1)$ & \multirow[t]{2}{*}{$<0.001$} \\
\hline Very well & $107(19.7)$ & $43(7.9)$ & \\
\hline \multicolumn{4}{|l|}{ Previous met } \\
\hline No previous contact & $245(45.1)$ & $294(54.1)$ & \multirow[t]{4}{*}{$<0.001$} \\
\hline First met $<1$ month ago & $73(13.4)$ & $83(15.3)$ & \\
\hline First met $1-6$ months ago & $92(16.9)$ & $80(14.7)$ & \\
\hline First met $>6$ months ago & $133(24.5)$ & $86(15.8)$ & \\
\hline \multicolumn{4}{|l|}{ Previous sex } \\
\hline No previous sexual contact & $300(55.2)$ & $368(67.8)$ & \multirow[t]{2}{*}{$<0.001$} \\
\hline Some previous sexual contact & $243(44.8)$ & $175(32.2)$ & \\
\hline \multicolumn{4}{|l|}{ Previous anal sex } \\
\hline No previous anal intercourse & $322(59.3)$ & $392(72.2)$ & \multirow[t]{2}{*}{$<0.001$} \\
\hline Any previous anal intercourse & $221(40.7)$ & $151(27.8)$ & \\
\hline \multicolumn{4}{|l|}{ Tell own HIV serostatus } \\
\hline No & $247(45.5)$ & $327(60.2)$ & \multirow[t]{2}{*}{$<0.001$} \\
\hline Yes & $296(54.5)$ & $216(39.8)$ & \\
\hline \multicolumn{4}{|l|}{ Did he tell his HIV serostatus? } \\
\hline No & $295(54.3)$ & $359(66.1)$ & \multirow[t]{2}{*}{$<0.001$} \\
\hline Yes & $248(45.7)$ & $184(33.9)$ & \\
\hline \multicolumn{4}{|c|}{ Confident about his HIV serostatus? } \\
\hline No & $149(27.4)$ & $165(30.4)$ & \multirow[t]{2}{*}{0.185} \\
\hline Yes & $394(72.6)$ & $378(69.6)$ & \\
\hline \multicolumn{4}{|c|}{ Belief to be concordant with partner? } \\
\hline Not seroconcordant & $297(54.7)$ & $385(70.9)$ & \multirow[t]{2}{*}{$<0.001$} \\
\hline Seroconcordant & $246(45.3)$ & $158(29.1)$ & \\
\hline \multicolumn{4}{|l|}{ Trust partner? } \\
\hline No & $180(33.1)$ & $187(34.4)$ & \multirow[t]{2}{*}{0.630} \\
\hline Yes & $363(66.9)$ & $356(65.6)$ & \\
\hline \multicolumn{4}{|c|}{ UAIC: Why no condom: because I trusted him } \\
\hline \multicolumn{4}{|c|}{$\begin{array}{l}\text { PAIC: Why used a condom: because } \\
\text { I wasn't sure I should trust him }\end{array}$} \\
\hline No & $157(28.9)$ & $248(45.7)$ & \multirow[t]{2}{*}{$<0.001$} \\
\hline Yes & $386(71.1)$ & $295(54.3)$ & \\
\hline
\end{tabular}

Of occasions when men engaged in PAIC, $80.1 \%$ believed their partner was seroconcordant: $3.1 \%$ believed they were seroconcordant HIV-positive and $77.0 \%$ believed they were seroconcordant HIV-negative.

On occasions when men engaged in UAIC, they were more likely to report that they knew their partner very well than on occasions when they engaged in PAIC (Table 2). More than half of the men had met their partner before when they engaged in UAIC, compared to less than half on occasions when they engaged in PAIC; they were also likely to have known their UAIC partners longer than their PAIC partners. On occasions when men engaged in UAIC 
they were more likely to have had previous sex with this partner, than on occasions when they engaged in PAIC. Among the 69 men who had previously met their most recent UAIC partner but had not previously had sex with him, twelve of these men (17.4\%) nonetheless considered they knew that partner well, whereas, among the 229 men who had previously met their most recent UAIC and had previously had sex with him, $92(40.2 \%)$ felt they knew this partner well. On occasions when they used condoms, men were somewhat less likely to indicate that they knew their partners well, but tendency for men who had previously had sex with their partner to feel that they knew these partners well was nonetheless also applied to these situations as well. Among the ninety men who had previously met their most recent PAIC partner but had not previously had sex with him, eight of these men $(8.9 \%)$ nonetheless considered they knew that partner well, while, among the 159 men who had previously met their most recent PAIC and had previously had sex with him, 35 (22.0\%) felt they knew this partner well.

\section{Multivariate Analysis}

In the PCA, five PCs with an eigenvector that had an eigenvalue greater than one were retained. The first two factors were used in the further analysis because these contained approximately $40 \%$ of the variance, and were associated with relevant interpretations. Table 3 shows the PC loadings and mean values of the PCs.

\section{Familiarity}

The variables referring to whether the respondent and his most recent casual partner had previously met, had previously had sex, and had previously had anal intercourse all loaded positively onto PC 1 (Table 3 ). Hence, PC 1 can be interpreted to represent the degree of intimate familiarity a man has with his most recent casual sex partner. On occasions when men engaged in UAIC, PC 1 was significantly higher than on occasions when men engaged in PAIC (Table 4), indicating that men were more familiar with their casual partner on occasions of UAIC than PAIC.

\section{Disclosure}

The variables referring to whether the respondent had told his most recent casual partner his own HIV serostatus, had been informed by his partner of his HIV serostatus, was confident about his partner's HIV serostatus, and whether they believed they were HIV seroconcordant all loaded positively onto PC 2 (Table 3). Hence, PC 2 can be interpreted to represent the degree of disclosure a man has with his most recent casual partner. On occasions when men engaged in UAIC, PC 2 was significantly higher than on occasions when men engaged in PAIC (Table 4), indicating that men had a higher degree of disclosure with their casual partner on occasions of UAIC than on occasions of PAIC.

In the PCA, we also investigated the association between familiarity and disclosure of HIV serostatus, and UAIC separately for HIV-positive/and HIV-negative respondents. No differences in the findings were observable for either HIV-positive or HIV-negative men.

\section{Hierarchical Cluster Analysis}

The HCA independently corroborated the results of the PCA described. Three clusters were identified. Men in cluster 1 were less likely to believe their partner was HIVpositive; to have previously had sex, including anal intercourse with their partner; or to know their partner well. This represents a group of men with low familiarity with

Table 3 Description of the factors, derived from the principal component analysis (PCA)

\begin{tabular}{|c|c|c|c|c|c|}
\hline & \multirow[t]{2}{*}{ Question $^{\mathrm{b}}$} & \multicolumn{2}{|c|}{$\begin{array}{l}\text { Mean value of principal } \\
\text { component }\end{array}$} & \multicolumn{2}{|c|}{$\begin{array}{l}\text { Principal component } \\
\text { loading }^{\mathrm{a}}\end{array}$} \\
\hline & & No & Yes & PC 1 & $\mathrm{PC} 2$ \\
\hline \multirow[t]{3}{*}{ PC 1} & Did the respondent have anal sex with the last casual partner before? & -0.664 & 1.297 & 0.98 & \\
\hline & Did the respondent have sex with the last casual partner before? & -0.749 & 1.207 & 1.00 & \\
\hline & Had the respondent met the last casual partner before? & -0.184 & 0.811 & 0.74 & \\
\hline \multirow[t]{4}{*}{ PC 2} & Is the respondent confident about partner's HIV serostatus? & -1.002 & 0.401 & & 0.55 \\
\hline & Did respondents' partner tell the HIV serostatus? & -0.583 & 1.181 & & 0.87 \\
\hline & Did the respondent tell his own HIV serostatus? & -0.733 & 0.814 & & 0.85 \\
\hline & Was the respondent concordant with the last casual partner? & -0.839 & 0.559 & & 0.69 \\
\hline
\end{tabular}

\footnotetext{
${ }^{a}$ Only factor loading $>10.41$ are presented

b Only questions with at least 1 principal component loading $>|0.4|$ are presented
} 
Table 4 Mean values of the two factors for PAIC and UAIC, including $P$-values

\begin{tabular}{llll}
\hline & PAIC & UAIC & $P$-value* \\
\hline PC 1 & -0.141 & 0.143 & 0.003 \\
PC 2 & -0.203 & 0.206 & $<0.001$ \\
\hline
\end{tabular}

* $P$-value from a repeated measures multivariable logistic regression

their casual sex partner. Men in cluster 2 were less likely to have previously met their partner, or had sex, including anal intercourse; or to know their partner well. It was also less likely that their partner told them their HIV serostatus. This represents a group of men with low familiarity and a low degree of disclosure with their casual sex partner. Men in cluster 3 were more likely to have previously met their partner, or had sex, including anal intercourse, with their partner; to trust their partner; and to be confident about their partner's HIV serostatus. This represents a group of men with high familiarity and a high degree of disclosure with their casual sex partner. Cluster 1 and 2 represent occasions when men were more likely to have engaged in PAIC, cluster 3 represents occasions when men were more likely to have engaged in UAIC $(P<0.001)$. Therefore, on occasions when men engaged in UAIC they had a higher degree of familiarity and disclosure than during occasions of PAIC.

\section{Discussion}

Our findings indicate that familiarity with casual partners, and disclosure of HIV serostatus were positively associated with UAIC, as found in other studies [15, 16]. Familiarity in this study was comprised of several different components: Prior acquaintance; previous sexual contact; how well men felt they knew their partners; how much they believed they could trust their partners; knowledge and disclosure of HIV serostatus; and confidence in their knowledge of partners' HIV serostatus.

Previously, Zablotska et al. [16] examined the association between: (i) measures of how well gay men knew their casual sex partners and HIV serostatus; and (ii) discussion of condom use prior to sex and whether they had previously had sex with that casual partner. Additionally, they assessed the relationship between UAI and ever having sex with the last casual partner before, and match of serostatus. We explored some of these same themes. However, the analysis used here provides additional perspective into multivariate predictors that drive the decision to use condoms at a casual sex encounter. This decision is complex and multifaceted. We have explored this complexity in greater detail to simultaneously combine data from multiple variables, including several different indicators of familiarity. Groups of these variables were interpreted together, and these groups of variables were tested for an association with the decision to use condoms at casual sex encounters. This analysis resulted in multivariable profiles (familiarity and disclosure) that significantly drive the decision to use condoms at a casual sex encounter, providing additional insight into the issues raised by Zablotska et al. [16].

Although univariate analysis showed little difference in trust and confidence when men engaged in either UAIC or PAIC, the multivariate analyses showed that men were more confident about partners' HIV serostatus when they engaged in UAIC and the HCA showed they were more likely to trust their partner on those occasions. This greater trust and confidence may have influenced the association between familiarity and disclosure, and UAIC, particularly as most men believed their partners were most likely seroconcordant, whether they used a condom or not: Presumably an abstract belief that their partner was seroconcordant needed to be supported by direct information and a degree of trust. Disclosure of HIV serostatus was more likely as men became more familiar with their casual partners. This suggests that revealing or discussing one's HIV serostatus is a marker of intimacy and growing trust between partners [1, 14]. If they know each other, and have discussed HIV serostatus, trust each other and are quite confident about their partners' HIV serostatus, the degree of risk involved may be reduced and these men may therefore be at lower risk than might be otherwise assumed. However, to what extent their risk is reduced would undoubtedly be dependent on the quality of their communication with, and knowledge about, each other. Regardless, men who engage in UAIC without familiarity, disclosure, confidence and trust are probably men at highest risk.

It is likely that the degree of familiarity between men also influences the degree of trust: When men were more familiar with their partners they trusted their partners more. The sense of trust between casual partners is often associated with greater communication about partner' HIV serostatus. In some cases, however, trust may be unreasonable and therefore result in assumptions about partners HIV serostatus, without adequate discussion of condom use and HIV serostatus. Some men may require specific tools to assist them in discussing and communicating HIV serostatus with casual partners, and opportunities to reflect on their understandings and beliefs about familiarity with, and trust in, their casual partners, so they can better assess the degree of risk involved and their need to negotiate condom use with those partners. The minority of the men who engage in UAIC yet remain relatively unfamiliar with their partners and who do not discuss HIV serostatus, suggest very specific challenges for HIV prevention. In these 
circumstances, condom use would clearly be the sensible option, but they have chosen otherwise. The reasons for having chosen not to use condoms when they know little about their sexual partners are most likely very different to those on occasions when they have an intimate, and seemingly reliable, degree of familiarity with, and knowledge about, their partners. Men's attitudes to HIV prevention and risk-reduction strategies are likely to be very different in these two sets of circumstances requiring quite different sorts of interventions.

Our study has certain limitations. We were unable to examine incidence and therefore cannot comment on the likelihood for familiarity to be a factor in HIV infection. Also, familiarity with casual partners may have stimulated UAIC or may have been used as a justification afterwards. In considering these findings, there may be differences between the Australian context, where testing for HIV is relatively high among gay men, and the situation in other countries. Also, this was a volunteer convenience sample and may not be entirely representative of all homosexually active men in Australia. It is difficult to assess the representativeness of samples of homosexually active men due to lack of appropriate sexuality indicators in population based research [17]. Nonetheless, this is a large sample with strong similarities to other samples obtained in Australia, including the samples obtained in the Australian gay men's behavioral surveillance system, data from which have been found to closely predict trends in HIV incidence within this population [18]. Regarding the data concerning the most recent sexual events, those events and the men's partners at those events may not have been representative of all their recent sexual events. Despite these limitations, our study provides a relevant insight into the influence of familiarity with casual partners and disclosure of HIV serostatus on UAIC. Further research may explore the association between familiarity and UAIC, and disclosure of HIV serostatus and UAIC prospectively, so causality of HIV infection can be established.

Acknowledgments The authors thank the men who participated in the Pleasure and Sexual Health study. The Kirby Institute and The Australian Research Centre in Sex, Health and Society (ARCSHS) receive funding from the Australian Government Department of Health and Ageing. The Kirby Institute is affiliated with the Faculty of Medicine, University of New South Wales. ARCSHS is affiliated with La Trobe University. No pharmaceutical grants were received in the development of this study.

Conflict of interest All authors declare that they have no conflicts of interest

Open Access This article is distributed under the terms of the Creative Commons Attribution Noncommercial License which permits any noncommercial use, distribution, and reproduction in any medium, provided the original author(s) and source are credited.

\section{References}

1. Prestage G, Van de Ven P, Grulich A, Kippax S, Mcinnes D, Hendry O. Gay men's casual sex encounters: discussing HIV and using condoms. AIDS Care. 2001;13:77-84.

2. Van de Ven P, Kippax S, Crawford J. In a minority of gay men, sexual risk practice indicates strategic positioning for perceived risk reduction rather than unbridled sex. AIDS Care. 2002;14: 471-80.

3. Prestage GP, Mao L, Kippax S. Use of viral load to negotiate condom use among gay men in Sydney, Australia. AIDS Behav. 2009; 13(4):645-51.

4. Jin F, Crawford J, Prestage GP. Unprotected anal intercourse, risk reduction behaviours, and subsequent HIV infection in a cohort of homosexual men. AIDS. 2009;23(2):243-52.

5. Gold RS, Skinner MJ, Hinchy J. Gay men's stereotypes about who is HIV infected: a further study. Int J STD AIDS. 1999;10(9):600-5.

6. O'Leary A. Positive living: the sexual lives of seropositive gay and bisexual men. In: Halkitis PN, Gomez CA, Wolitski RJ, editors. Guessing games: sex partner serostatus assumptions among HIV-positive gay and bisexual men. Washington: American Psychological Association; 2007.

7. Zablotska IB, Imrie J, Prestage G, et al. Gay men's current practice of HIV seroconcordant unprotected anal intercourse: serosorting or seroguessing? AIDS Care. 2009;21:501-10.

8. Crosby R, Mettey A. A descriptive analysis of HIV risk behavior among men having sex with men attending a large sex resort. J Acquir Immune Defic Syndr. 2004;37(4):1496-9.

9. Pedrana A, Stoove M, Guy R, et al. "Suck it and See..." Estimating HIV prevalence and unrecognised HIV infection among men who have sex with men in Victoria. Victorian Department of Health Report. Melbourne. Burnet Institute; 2009.

10. Zablotska I, Frankland A, Prestage GP, Down I, Ryan D. Sydney gay community periodic survey: February 2008. Sydney: Monograph, National Centre in HIV Social Research; 2008.

11. Mao L, Crawford JM, Hospers HJ. 'Sero-sorting' in casual anal sex of HIV-negative gay men is noteworthy and is increasing in Sydney, Australia. AIDS. 2006;20:1204-6.

12. Koblin BA, Chesney MA, Husnik MJ, et al. EXPLORE Study Team. High-risk behaviors among men who have sex with men in 6 US cities: baseline data from the EXPLORE study. Am J Public Health. 2003;93:926-32.

13. Davidovich U, de Wit JB, Stroebe W. Behavioral and cognitive barriers to safer sex between men in steady relationships: implications for prevention strategies. AIDS Educ Prev. 2004;16(4):304-14.

14. Holt M, Rawstorne P, Worth H, Bittman M, Wilkinson J, Kippax S. Predictors of HIV disclosure among untested, HIV-negative and HIVpositive Australian men who had anal intercourse with their most recent casual male sex partner. AIDS Behav. 2009;15(6):1128-39.

15. Prestage G, Jin F, Grulich A, de Wit J, Zablotska I. Gay men are less likely to use condoms with casual sex partners they know 'well'. AIDS Behav. 2011.

16. Zablotska IB, Grulich AE, De Wit J, Prestage G. Casual sexual encounters among gay men: familiarity, trust and unprotected anal intercourse. AIDS Behav. 2010;15(3):607-12.

17. Madeddu D, Richters J, Ferris J, Grierson J, Smith A, Allan B, Grulich AE, Prestage GP. Estimating population distribution and HIV prevalence among homosexual and bisexual men. Sex Health. 2006;3:37-43.

18. Zablotska I, Prestage GP, Middleton M, Wilson D, Grulich AE. Contemporary trends in HIV diagnoses in Australia can be predicted by trends in unprotected anal intercourse among gay men. AIDS. 2010;24:1955-66. 